\title{
Different risk factors for peripheral vascular calcification between diabetic and non-diabetic haemodialysis patients - importance of glycaemic control
}

\author{
E. Ishimura ${ }^{1}$, S. Okuno ${ }^{4}$, K. Kitatani ${ }^{4}$, M. Kim ${ }^{4}$, T. Shoji ${ }^{2}$, T. Nakatani ${ }^{3}$, M. Inaba ${ }^{2}$, Y. Nishizawa ${ }^{2}$ \\ ${ }^{1}$ Department of Nephrology, ${ }^{2}$ Department of Endocrinology, Metabolism, and Molecular Medicine, ${ }^{3}$ Department of Urology, \\ Osaka City University Graduate School of Medicine, Osaka, Japan \\ ${ }^{4}$ Shirasagi Hospital Kidney Center, Osaka, Japan
}

\begin{abstract}
Aim/hypothesis. Although derangements of calcium and phosphate control have been emphasized as important risk factors for vascular calcification in nondiabetic haemodialysis patients, similar risk factors for diabetic haemodialysis patients are not known. We compared factors affecting peripheral vascular calcification between haemodialysis patients with and without diabetes.

Methods. We examined 421 patients on maintenance haemodialysis. There were 89 patients with Type II (non-insulin-dependent) diabetes mellitus (53 men and 36 women, $62 \pm 10$ years old) and 332 patients without diabetes (192 men and 140 women, 59 \pm 13 years old). Hand roentgenography was carried out, and visible vascular calcification of the hand arteries was evaluated.

Results. There were 42 diabetic patients and 45 nondiabetic patients with vascular calcification. The prevalence of vascular calcification in diabetic patients
\end{abstract}

(47.1\%) was higher than in non-diabetic patients $(13.6 \%)(p<0.001)$. In multivariate logistic regression, the main factors affecting vascular calcification in non-diabetic patients were advanced age, longer duration of haemodialysis, increased phosphate concentrations, male gender, and lower predialysis diastolic pressure. In diabetic patients, predictors for vascular calcification were higher values of $\mathrm{HbA}_{1 \mathrm{C}}$ and longer duration of haemodialysis. In diabetic patients, a $1 \%$ increase in $\mathrm{HbA}_{1 \mathrm{C}}$ increased the risk of calcification by 2.1 -fold (95\% CI 1.282-3.575, $p=0.0029$ ).

Conclusion/interpretation. We have shown that poor glycaemic control, rather than calcium and phosphate concentrations, is a predictor of peripheral vascular calcification in diabetic patients on haemodialysis. This study emphasizes that glycaemic control remains critical even in diabetic patients with end-stage renal disease. [Diabetologia (2002) 45:1446-1448]

Keywords Vascular calcification, end-stage renal failure, Type II diabetes, glycaemic control, phosphate.
The population of diabetic patients has increased dramatically, and the leading cause of end-stage renal disease is diabetic nephropathy, in Japan, the United

Received: 14 April 2002 / Revised: 3 June 2002

Published online: 16 August 2002

(C) Springer-Verlag 2002

Corresponding author: E. Ishimura, MD, PhD, Department of Nephrology, Osaka City University Graduate School of Medicine, 1-4-3, Asahi-machi, Abeno-ku, Osaka 545-8585, Japan.

E-mail: ish@med.osaka-cu.ac.jp
States, and Europe. Vascular calcification, which increases cardiovascular and other causes of mortality $[1,2]$, is highly prevalent in dialysis patients. Factors affecting vascular calcification in dialysis patients include advanced age, derangement of calcium-phosphate metabolism [2, 3, 4], and diabetes [5, 6, 7]. However, specific factors affecting vascular calcification have not been studied using large numbers of diabetic haemodialysis patients. We compared factors affecting peripheral vascular calcification between haemodialysis patients with and without diabetes and 
found that the strongest predictor for vascular calcification in haemodialysis patients with diabetes is poor glycaemic control.

\section{Subjects and methods}

A total of 501 patients with haemodialysis for more than 3 months were in treatment at Shirasagi Hospital Kidney Center in December 1999, including 109 patients with diabetes and 392 patients without diabetes. Of these, 89 patients with diabetes and 332 patients without diabetes gave their informed consent, and their clinical data were obtained. This percentage of diabetics patients $(21.1 \%)$ is close to the ratio of the entire dialysis population in Japan at the end of 1999 (25.1\%, $n=185$ 688). Diabetic patients in our cohort consisted of 53 men and 36 women, and their ages ranged from 37 to 79 years old $(62 \pm 10$; means \pm SD). Of 89 patients, 42 were treated with insulin, 22 with oral antidiabetic drugs, and 25 with diet only. Patients without diabetes in our cohort consisted of 192 men and 140 women, and their age ranged from 28 to 87 years old $(59 \pm 13$; means \pm SD). There were no significant differences in the male-to-female ratio or age between diabetic and non-diabetic patients. The duration of haemodialysis in diabetic patients was significantly shorter than that of non-diabetic patients $(56 \pm 39$ months vs $102 \pm 74$ months, respectively, $p<0.001)$.

In December 1999, hand roentgenography was carried out in each patient at a voltage of $45 \mathrm{kV}$. Vascular calcification of the hand arteries distal to the wrist joints was evaluated by one of the authors who was unaware of other patient data. Blood was taken before dialysis in a non-fasting condition to measure $\mathrm{HbA}_{1 \mathrm{C}}$ (in diabetic patients only) and serum calcium and phosphate (in all patients). The mean values of three measurements during the 3 months before roentgenography were used for analysis. Serum intact parathyroid hormone (intact PTH) was measured once at the time of roentogenography.

Data were expressed as the means $\pm \mathrm{SD}$. A chi-squared test was used to compare the prevalence of vascular calcification of the hand arteries between diabetic and non-diabetic patients. Unpaired Student's $t$ test was used to compare clinical parameters between patients with and without vascular calcification. Multivariate logistic regression analyses were used to explore the combined effect of factors affecting vascular calcification.

\section{Results}

Of 332 non-diabetic patients, there were 45 patients $(13.6 \%)$ with vascular calcification and of 89 diabetic patients, there were 42 patients $(47.1 \%)$ with vascular calcification. The prevalence of vascular calcification in diabetic patients was higher than in non-diabetic patients $(p<0.001)$.

Between non-diabetic patients with and without vascular calcification, differences were seen in phosphate concentration $(2.04 \pm 0.42$ vs $1.84 \pm 0.39 \mathrm{mmol} / \mathrm{l}$, $p<0.001)$, duration of haemodialysis $(151 \pm 86$ vs $94 \pm 79$ months, $p<0.001)$, predialysis diastolic pressure $(41 \pm 22$ vs $51 \pm 19 \mathrm{mmHg}, p<0.005)$, age $(64 \pm 10$ vs $57 \pm 12$ years, $p<0.05)$, and male to female ratio (vascular calcification in 33 men vs 12 women, $p<0.05$, chi-square test). Between diabetic patients
Table 1. Factors affecting vascular calcification in non-diabetic haemodialysis patients $(n=332)$

\begin{tabular}{llll}
\hline & OR & $95 \%$ CI & $p$ value \\
\hline Age (years) & 1.082 & $1.039-1.127$ & 0.0001 \\
$\begin{array}{l}\text { Duration of dialysis } \\
\quad \text { (years) }\end{array}$ & 1.128 & $1.065-1.195$ & 0.0001 \\
$\begin{array}{l}\text { Phosphate (mmol/l) } \\
\text { Male (vs female) }\end{array}$ & 6.006 & $2.064-17.478$ & 0.0010 \\
$\begin{array}{l}\text { Diastolic blood pressure } \\
\quad(m m H g)\end{array}$ & 0.972 & $0.953-0.9993$ & 0.0075 \\
$\begin{array}{l}\text { Systolic blood pressure } \\
\quad(m m H g)\end{array}$ & 1.020 & $0.9997-1.043$ & 0.0906 \\
$\begin{array}{l}\text { Smoking } \\
\quad(\text { vs non-smoking) }\end{array}$ & 1.417 & $0.577-3.480$ & 0.3741 \\
$\begin{array}{l}\text { Calcium (mmol/l) } \\
\text { Kt/V }\end{array}$ & 0.513 & $0.045-5.897$ & 0.5918 \\
Intact PTH (ng/l) & 0.778 & $0.087-6.990$ & 0.8224 \\
& 1.000 & $0.998-1.002$ & 0.9277 \\
& & $\mathrm{R}^{2}=0.231$ & $p<0.0001$ \\
\hline
\end{tabular}

iPTH, intact parathyroid hormone; $\mathrm{R}^{2}$, multiple coefficient of variation

Table 2. Factors affecting vascular calcification in diabetic haemodialysis patients $(n=89)$

\begin{tabular}{llll}
\hline & OR & $95 \%$ CI & $p$ value \\
\hline Haemoglobin A1C (\%) & 2.141 & $1.282-3.575$ & 0.0029 \\
Duration of dialysis (years) & 1.223 & $1.014-1.476$ & 0.0354 \\
Intact PTH (ng/l) & 1.006 & $0.998-1.015$ & 0.1569 \\
Phosphate (mmol/l) & 0.390 & $0.100-1.522$ & 0.1755 \\
Age (years) & 0.979 & $0.920-1.041$ & 0.4934 \\
Diastolic pressure (mmHg) & 1.011 & $0.979-1.044$ & 0.4952 \\
Smoking (vs non-smoking) & 0.648 & $0.185-2.269$ & 0.4974 \\
Kt/V & 0.364 & $0.012-11.400$ & 0.5655 \\
Systolic pressure (mmHg) & 1.009 & $0.976-1.042$ & 0.6030 \\
Male (vs female) & 1.328 & $0.252-6.997$ & 0.7376 \\
Calcium (mmol/l) & 0.962 & $0.019-48.780$ & 0.9845 \\
& & $\mathrm{R}^{2}=0.185$ & $p<0.0001$ \\
\hline
\end{tabular}

iPTH, intact parathyroid hormone; $\mathrm{R}^{2}$, multiple coefficient of variation

with and without vascular calcification, differences were seen in $\mathrm{HbA}_{1 \mathrm{C}}(7.0 \pm 1.4$ vs $6.1 \pm 0.9 \%, p<0.01)$, duration of haemodialysis ( $68 \pm 43$ vs $45 \pm 32$ months, $p<0.05)$, and intact PTH concentrations $(172 \pm 194$ vs $100 \pm 93 \mathrm{pg} / \mathrm{ml}, p<0.05)$. Neither blood pressure nor the prevalence of insulin therapy differed.

Multivariate logistic regression analyses were done to explore the combined effect of factors affecting vascular calcification. In non-diabetic patients such factors were advanced age, longer duration of haemodialysis, increased phosphate concentrations, male gender, and lower predialysis diastolic pressure (Table 1). In diabetic patients, significant predictors for vascular calcification were higher values of $\mathrm{HbA}_{1 \mathrm{C}}$ and longer duration of haemodialysis (Table 2). The latter analysis showed that a $1 \%$ increase in $\mathrm{HbA}_{1 \mathrm{C}}$ increased the risk of calcification by 2.1 -fold $(95 \% \mathrm{CI}$ 
1.282-3.575, $p=0.0029$ ), suggesting that poor glycaemic control is a strong risk factor for vascular calcification.

\section{Discussion}

We examined medial vascular calcification [1], which, in haemodialysis patients, is a predictor for mortality $[2,3,4]$. A pathophysiological mechanism is thought to be increased stiffness of calcified arteries, which causes higher left ventricular afterload [4, 8]. Factors affecting vascular calcification in haemodialysis patients have emphasised the importance of calciumphosphate metabolism, particularly secondary hyperparathyroidism and overuse of calcium salts (phosphate binders) $[2,3,4]$. We found that the phosphate concentration was higher in those with vascular calcification than in non-diabetic patients without vascular calcification $(p=0.0003)$. In the former group, although the calcium-phosphorus ion product was higher $(p=0.0058)$, the statistical significance of the phosphate concentration was greater. In haemodialysis patients, hyperlipidaemia is reported to be unrelated to cardiovascular disease or cardiac calcification $[5,6$, 7]. In this study, total cholesterol and triglycerides concentrations were not different between patients with and without vascular calcification either in nondiabetic or in diabetic patients, although blood was taken under non-fasting conditions.

There are, however, no studies of predictors for vascular calcification in diabetic haemodialysis patients, although diabetes has been emphasized to be a strong risk factor for atherosclerotic cardiovascular disease, cardiac calcification and peripheral vascular disease in chronic haemodialysis patients [5, 6, 7]. Our study showed a higher incidence of vascular calcification in diabetic patients on maintenance haemodialysis compared to non-diabetic haemodialysis patients. Predictors for vascular calcification also differed between non-diabetic and diabetic patients. The former included advanced age, longer duration of dialysis, higher phosphate concentrations, male gender, and lower predialysis diastolic pressure, consistent with previous studies [2, 3, 4, 5, 6, 7]. However, the most significant predictor in diabetic patients was higher $\mathrm{HbA}_{1 \mathrm{C}}$, while phosphate and calcium were not significant. This study shows that risk factors for vascular calcification differ in diabetic and non-diabetic patients with end-stage renal failure. Although glycaemic control is emphasised in diabetic patients to prevent progression of nephropathy before the need for dialysis $[9,10]$, our findings provide new evidence that glycaemic control remains critical in end-stage renal disease. Glycaemic control is therefore important even in diabetic patients with end-stage renal disease.

\section{References}

1. Lehto S, Niskanen L, Suhonen M, Ronnemaa T, Laakso M (1996) Medial artery calcification. A neglected harbinger of cardiovascular complication in non-insulin-dependent diabetes mellitus. Arterioscler Thromb Vasc Biol 16: 978983

2. Davies MR, Fruska KA (2001) Pathophysiological mechanisms of vascular calcification in end-stage renal disease. Kidney Int 60: 472-479

3. Cozzolino M, Dusso AS, Slatopolsky E (2001) Role of calcium-phosphate product and bone-associated proteins on vascular calcification in renal failure. J Am Soc Nephrol 12: $2511-2516$

4. Goodman WG, Salusky IB (2001) Non-invasive assessments of cardiovascular disease in patients with renal failure. Curr Opin Nephrol Hypertens 10: 365-369

5. O'Hare AM, Hsu CY, Bacchetti P, Johansen KL (2002) Peripheral vascular disease risk factors among patients undergoing hemodialysis. J Am Soc Nephrol 13: 497-503

6. Raggi P, Boulay A, Chasan-Taber S et al. (2002) Cardiac calcification in adult hemodialysis patients. A link between end-stage renal disease and cardiovasculand disease? J Am Coll Cardiol 39: 695-701

7. Cheung AK, Sarnak MJ, Yan G et al. (2000) Athelosclerotic cardiovascular disease risks in chronic hemodialysis patients. Kidney Int 58: 353-362

8. Guerin AP, London GM, Marchais SJ, Metivier F (2000) Arterial stiffening and vascular calcifications in end-stage renal disease. Nephrol Dial Transplant 15: 1014-1021

9. Breyer JA, Bain RP, Evans JK et al. (1996) Predictors of the progression of renal insufficiency in patients with insulin-dependent diabetes and overt diabetic nephropathy. The Collaborative Study Group. Kidney Int 50: 1651-1658

10. UK Prospective Diabetes Study (UKPDS) Group (1998) Intensive blood-glucose control with sulphonylureas or insulin compared with conventional treatment and risk of complications in patients with type 2 diabetes (UKPDS 33). Lancet 352: 837-853 